\title{
Evaluation of anti-cancer activity of Ruellia tuberosa on EAC induced mammary tumor
}

\author{
V. Nagarjuna Reddy*, Nagarathna P. K. M, M. Divya \\ Department of Pharmacology, Karnataka College of Pharmacy, Bangalore, India \\ *Corresponding authorE-mail: 9naga9@gmail.com
}

\begin{abstract}
Aim of the study was to study the antitumor effect of Ruellia tuberosa. The activity of methanolic extracts of 250, 500 $\mathrm{mg} / \mathrm{kg}$ of Ruellia tuberosa leaves was evaluated against Ehrlich ascites carcinoma (EAC) tumor in mice. Acute and short-term toxicity studies were performed initially in order to ascertain the safety of methanolic extracts of Ruellia tuberosa. Tumour cells $(1 \times 106$ cells/mice) were injected into the right hind limb (thigh) of mammary tumour group animals subcutaneously and the tumour is allowed to develop for 11 days and the treatment is started from 12th day for a period of 20 days. The effect of methanolic extracts of Ruellia tuberosa on the growth of tumor, life span of EAC bearing hosts and simultaneous alterations in the hematological profile and histopathological profile were estimated. The methanolic extracts of Ruellia tuberosa showed decrease in tumor size, average body weight, and mean survival time thereby increasing life span of EAC tumor bearing mice. Hematological profile reverted to more or less normal levels in extracts treated mice. Histopathology has minimal effects when compared but a significant variation is seen.
\end{abstract}

Keywords: Ruellia tuberosa, EAC induced cancer, Mammary tumor,5-flurouracil.

\section{Introduction}

Cancer is one of the leading causes of mortality worldwide and the failure of conventional chemotherapy to affect major reduction in the mortality indicates that new approaches are critically needed [1]. Due to enormous propensity of plants, which synthesize a variety of structurally diverse bioactive compounds? The plant kingdom is a potential source of chemical constituents with antitumor and cytotoxic activities. The rich and diverse plant sources of India are likely to provide effective anticancer agents. One of the best approaches in the search of anticancer agents from plant sources is the selection of plants based on ethno medical leads [2]. A number of natural products have been studied for anticancer activity on various experimental models. This has resulted in the availability of nearly 30 effective anticancer drugs [1]. The treatment of cancer has undergone major advances, which include benefits of combination chemotherapy as well as the incorporation of biologic therapy, and yielding significant improvements in survival over the past decade [3]. Improving the quality of life of patients living with cancer and dying from cancer is therefore an urgent humanitarian need. The natural medicines have played a great role to treat various disorders in humans including cancer. Antioxidants which can quench free radicals could act as cancer chemo-preventive agents [4]. Natural products are playing an important role as a source of effective anticancer a gents and it is significant that $60 \%$ of currently used anticancer agents are derived from natural sources, including plants, marine organism and micro-organism. The mechanism of interaction between many secondary metabolites and cancer cells has been studied extensively. In particular, there is growing interest in the pharmacological evaluation of various plants used in Indian traditional system of medicine. Plant-derived natural products like flavonoid, steroids, alkaloids and terpenoids have received considerable attention in recent years due to their diverse pharmacological activities, including antioxidant and anticancer activity. Antioxidants play an important role in inhibiting and scavenging radicals and thus, protecting humans against infection and degenerative diseases [1].

Ruellia tuberosa is an erect, suberect, or diffuse perennial herb up to $60-70 \mathrm{~cm}$ tall herb and belongs to family Acanthaceae, a native of Central America, introduced into Indian garden as ornament. It is used medicinally in West Indies, Central America, Guiana, and Peru. R. tuberosa is commonly known as "Cracker plant" [5], [7]. In Siddha system of medicine, leaves are given with liquid copal as remedy for gonorrhea and ear diseases [8], used in stomach cancer[9]. Dried and ground roots in dose of two ounces cause abortion and also used in sore eyes [10]. The herb also exhibits emetic activity and employed substitute of ipecac, also used in bladder stones and decoction of leaves used in 
treatment of Bronchitis [11]. In Suriname's traditional medicine system, it is used as anthelmintic and also in management of joint pain and strained muscles. In folk medicine, it has been used as diuretic, antipyretic, ant diabetic, antidotal, thirst-quenching agent and analgesic and anti-hypertensive activity [12], [13]. Ruellia tuberosa is used as cooling in urinary problem, uterine fibroids [14], [15]. It has recently been incorporated as a component traditional medicine system; it is used as anthelmintic and also in management of joint pain in an herbal drink in Taiwan [16]. It has been experimentally proved to possess antioxidant [17], antimicrobial [18], anticancer [19], gastroprotective activity [20], antinociceptive, and anti-inflammatory activity [21]. It is reported that it contains flavonoid, steroids, triterpenoids and alkaloid [22]. The isolation and the structural elucidation of flavonoid and their antiproliferative activity against HepG2 and KB cancer cell lines have been reported [23]. R. tuberosa. Having wide activities and contains flavanoids.

\section{Materials and methods}

\section{Animals:}

Eight to ten weeks old Swiss albino mice having weight $(25-30 \mathrm{gm})$ were purchased from NIMHANS Bangalore. They were housed, five per poly propylene cage under standard laboratory conditions at room temperature $\left(25^{\circ} \mathrm{C} \pm 2^{\circ} \mathrm{C}\right)$ with $12 \mathrm{~h}$ light / dark cycle. The animals were provided with pellet chow and water ad libitum. Ethical clearance was obtained from Institutional Animal Ethical Committee (IAEC) of Karnataka College of pharmacy, Bangalore.

Plant material and extract preparation:

The leaves of Ruellia tuberosa were collected from Thirupathi forest region

Thirupathi District, Andhra Pradesh, INDIA in the month of March 2013. This plant species were authenticated by Dr. K. Madhava Chetty, Assistant professor, Department of Botany, Sri Venkateswara University, Thirupathi, Andhra Pradesh, India. The collected plant material was washed thoroughly with water to remove the adhering soil, mud, and debris. All old insect damage or fungus infected leaves, and flowers were removed. The leaves were dried in the shade at room temperature to a constant mass. The plant material was coarsely powdered into coarse powder a warring blender. The powder was stored in an airtight container and protect from light.

$100 \mathrm{gm}$ powdered leaves parts were subjected to successive extraction in a Soxhlet extractor using methyl alcohol. The extract obtained was concentrated in a rotary shaker and evaporated to dryness to get constant weight.

Anti-tumour activity, experimental design:

Male Swiss Albino mice divided into 4 groups $(\mathrm{n}=6)$. All the groups were injected with EAC cells $(0.2 \mathrm{ml}$ of $1 \times 106$ cells/mouse) sub-cutaneously at the thigh region to cause mammary tumor. This was taken as day zero and the treatment starts on the twelfth day after induction of tumor cells. The parameters selected are checked accordingly for every five days. The extract is then administered to the mice except the control group. Standard group receives 5 Fluoro Uracil as standard drug. One group receives $250 \mathrm{mg}$ and the other receives $500 \mathrm{mg}$ of the extract. The parameters include the Mean survival time (MST), \% increase in life span (\%ILS), Body weight, tumor size, Hematological parameter, RBC, WBC, Hemoglobin, Histopathology of liver and kidney.

Mean survival time [24]:

Animals will be inoculated with EAC cells ( 1 X 106cells/mouse) on day ' 0 ' and the median survival time (MST) of each group, consisting of 6 mice will be noted. MST $=\frac{(\text { day of first death }+ \text { day of last death })}{2}$

\section{Percentage increase life span (\% ILS) [25] :}

The effect of the drugs on tumor growth was monitored by recording the mortality daily for a period of 6 weeks and percentage increase in life span (\%ILS) was calculated.

$\%$ ILS $=($ Mean survival of treated group/ Mean survival of control group $)-1 \times 100$

\section{Body weight:}

Body weights of the experimental mice were recorded both in the treated and control group at the beginning of the experiment (day 0) and sequentially on every 5 th day during the treatment period.

Tumor size [26]:

Tumour mass was measured from the 11th day of tumour induction. The measurement was carried out every 5 th day for a period of 30 days. The volume of tumour mass was calculated using the formula: $\mathrm{V}=4 / 3 \Pi \mathrm{r}^{2}$

Where ' $r$ ' is the mean of ' $\mathrm{r}$ ' ' and ' $\mathrm{r}$ ' ' which are the two independent radii of the tumour mass.

Effect on haematological parameters:

At the end of the experimental period, 6 mice of each group were sacrificed the next day after an overnight fast by cervical dislocation. Blood was collected by Retro-orbital route and used for the estimation Haemoglobin (Hb\%) content, red blood cell count (RBC)[27] and white blood cell count (WBC)[28]. 
Histopathological studies [29]:

A portion of liver and kidney of animals in all groups were stored in container for 12 hours in $10 \%$ formalin (10 ml of formaldehyde in $90 \mathrm{ml}$ of normal saline) solution and subjected to histopathological studies.

\section{Statistical Analysis:}

Values were represented as mean \pm SEM. Data were analysed by one-way analysis of variance (ANOVA) followed by Dunnett's test using statistical package for social sciences (SPSS) version 10.0. $\mathrm{P}<0.05$ was considered significant. The toxic control group was compared with the normal control group and all other treatment groups were compared with the toxic control group.

\section{Results and discussion}

Table.1: Effect of flavonoid of ruellia tuberosa(250,500mg/kg.po/day/20days),5 fluorouracil (20mg/kg.ip/day/20days) on eac induced mice (breast

\begin{tabular}{|c|c|c|c|c|c|}
\hline SL.NO. & GROUPS & $\begin{array}{c}\text { MEAN SURVIVAL } \\
\text { TIME(MST) }\end{array}$ & $\begin{array}{c}\text { \% INCREASE IN } \\
\text { LIFESPAN (\%ILS) }\end{array}$ & $\begin{array}{c}\text { BODY } \\
\text { WEIGHT(G) }\end{array}$ & $\begin{array}{c}\text { TUMOUR SIZE } \\
{\left[\mathrm{V}=4 / 3 \pi r^{2}\right]}\end{array}$ \\
\hline 1 & $\begin{array}{c}\text { GROUP } 1 \\
\text { (EAC } \\
\text { CONTROL) }\end{array}$ & $17.33 \pm 0.21$ & & $31.03 \pm 0.49$ & $3.15 \pm 0.04$ \\
\hline 2 & $\begin{array}{c}\text { GROUP } 2 \\
(\text { EAC+5-FLU) }\end{array}$ & $38.58 \pm 0.27 * * *$ & $96.19 \pm 0.04 * * *$ & $26.25 \pm 0.11 * * *$ & $0.58 \pm 0.03 * * *$ \\
\hline 3 & $\begin{array}{c}\text { GROUP } 3 \\
{[\text { EAC }+} \\
\text { RT(250MG })]\end{array}$ & $25.58 \pm 0.68 * * *$ & $52.16 \pm 0.01 * * *$ & $29.42 \pm 0.23 * * *$ & $2.11 \pm 0.04 * * *$ \\
\hline 4 & $\begin{array}{r}\text { GROUP } 4 \\
{[\text { EAC +RT }} \\
(500 \mathrm{MG})]\end{array}$ & $31.90 \pm 0.19 * * *$ & $86.28 \pm 0.10 * * *$ & $27.93 \pm 0.15 * * *$ & $1.11 \pm 0.12 * * *$ \\
\hline
\end{tabular}

Table 2: Effect of flavonoid of Ruellia tuberosa $(250,500 \mathrm{mg} / \mathrm{kg}$. po/day/20days $), 5$-Fluorouracil $(20 \mathrm{mg} / \mathrm{kg} . \mathrm{ip} / \mathrm{day} / 20$ days $)$ on EAC induced mice. Hematological parameter

\begin{tabular}{|c|c|c|c|c|}
\hline Sl.No & Groups & $\mathrm{Hb}(\mathrm{g} \%)$ & $\mathrm{RBC}\left(10^{6}{ }_{\text {cells } / \mathrm{mm}^{3}}^{3}\right)$ & WBC $\left(10^{3}{ }_{\text {cells } / \mathrm{mm}^{3}}^{3}\right)$ \\
\hline 1 & Group 1(normal control) & $15.23 \pm 0.12$ & $5.89 \pm 0.06$ & $6.44 \pm 0.02$ \\
\hline 2 & Group 2 (EAC control & $8.75 \pm 0.18$ & $3.14 \pm 0.03$ & $14.25 \pm 0.15$ \\
\hline 3 & Group $3($ EAC $+5-F l u)$ & $13.45 \pm 0.16 * * *$ & $4.29 \pm 0.05 * * *$ & $10.11 \pm 0.21 * * *$ \\
\hline 4 & Group $4[\mathrm{EAC}+\mathrm{RT}(250 \mathrm{mg})]$ & $9.45 \pm 0.17 * * *$ & $2.78 \pm 0.07 * * *$ & $12.45 \pm 0.52 * * *$ \\
\hline 5 & Group 5 [EAC + RT $(500 \mathrm{mg})]$ & $11.46 \pm 0.16^{* * *}$ & $3.68 \pm 0.04 * * *$ & $11.11 \pm 0.31 * * *$ \\
\hline
\end{tabular}

\section{Parameter detail discussion:}

The effect of flavonoid of Ruellia tuberosa on the survival of tumours-bearing mice is shown in Table No 1 . The MST for the EAC control group was $17.33 \pm 0.21$ days; whereas it was $25.58 \pm 0.68$ days for Ruellia tuberosa $(250 \mathrm{mg} / \mathrm{kg} / \mathrm{day}$ p.o) and 31.90 \pm 0.19 days for Ruellia tuberosa $(500 \mathrm{mg} / \mathrm{kg} /$ day i.p) treated groups. The MST $38.58 \pm 0.27$ for 5 Fluorouracil $(20 \mathrm{mg} / \mathrm{kg} /$ day p.o $)$ treated group.The ILS for Ruellia tuberosa $(250 \mathrm{mg} / \mathrm{kg} / \mathrm{day}$ p.o $)$ was increased to $52.16 \pm 0.01 \%$, for Ruellia tuberosa (500 mg/kg/day p.o) it was increased to $86.28 \pm 0 . \%$ and the MST of 5-Fluorouracil $(20 \mathrm{mg} / \mathrm{kg} /$ day p.o) was increased to $96.19 \pm 0.04 \%$ and is shown in Table 1 . There was reduction in the tumour volume of mice treated with the extract shown in Table 1. Tumour volume of EAC control animals (15th day) was $3.15 \pm 0.04 \mathrm{ml}$, whereas for the group treated with Ruellia tuberosa $(250 \mathrm{mg})$ it was $2.11 \pm 0.04 \mathrm{ml}$ and $1.11 \pm 0.12 \mathrm{ml}$ for Ruellia tuberosa $(500 \mathrm{mg})$. Fluorouracil treated group was $0.58 \pm 0.03 \mathrm{ml}$, thus produced a significant reduction in the tumour volume. The effect of Ruellia tuberosa and 5-Fluorouracil on the body weight of tumour-bearing mice is shown in Table 1. The body weight of the EAC control group was $31.03 \pm 0.49 \mathrm{~g}$, whereas it was $29.42 \pm 0.23 \mathrm{~g}$ for Ruellia tuberosa (250mg) and $27.93 \pm 0.15 \mathrm{~g}$ for Ruellia tuberosa $(500 \mathrm{mg})$ treated groups. The body weight for 5-Fluorouracil treated group was $26.25 \pm 0.11 \mathrm{~g}$. Hematological parameters of EAC control group on Day 15 showed significant changes when compared to the Vehicle control mice as shown in Table No.2. In EAC control the total WBC count was found to increase with a reduction in the haemoglobin content and the RBC count. On the other hand, flavonoid of Ruellia tuberosa treatment could change these altered parameters to near normal values in a dose dependent manner, and the highest dose of Ruellia tuberosa has produced a superior effect which is comparable to 5-Fluorouracil. 
Histopathology of Liver and Kidney of EAC induced mammary tumor
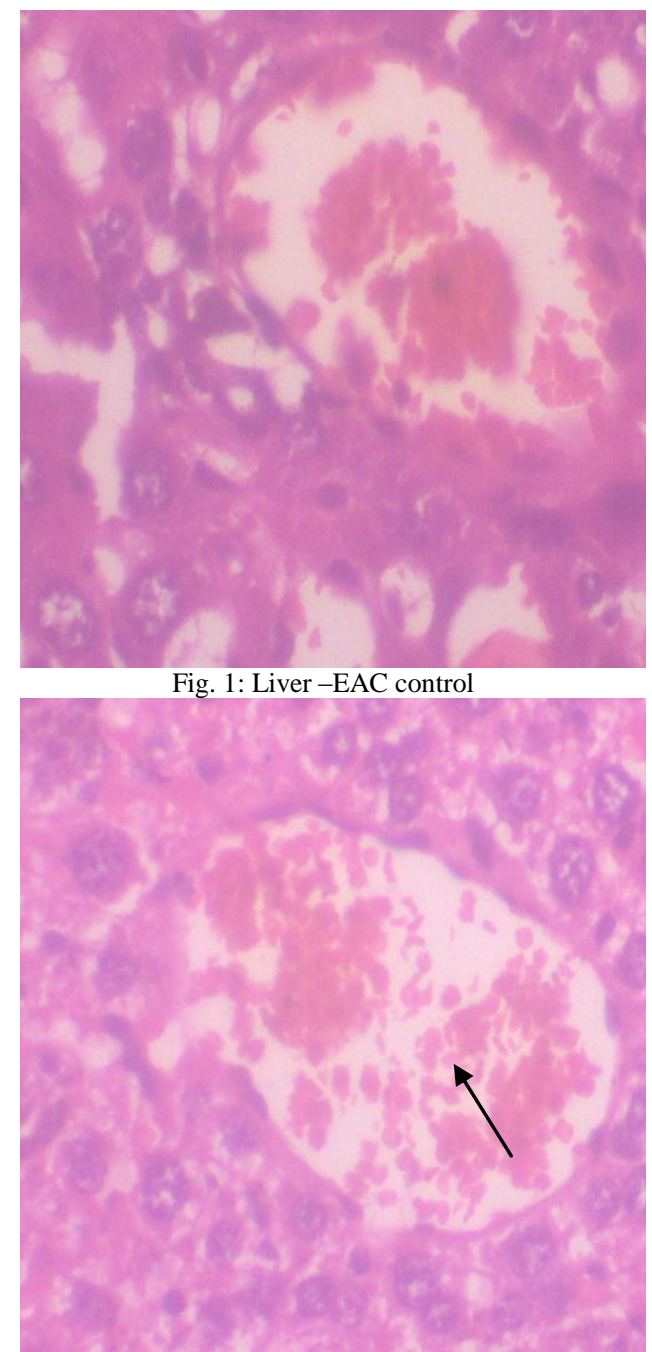

Fig. 3: Liver - Fluorouracil control

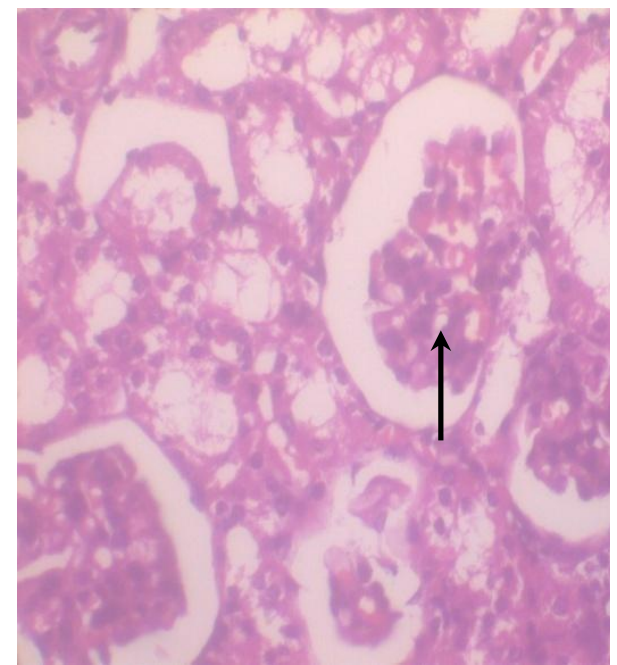

Fig. 2: Kidney - EAC control

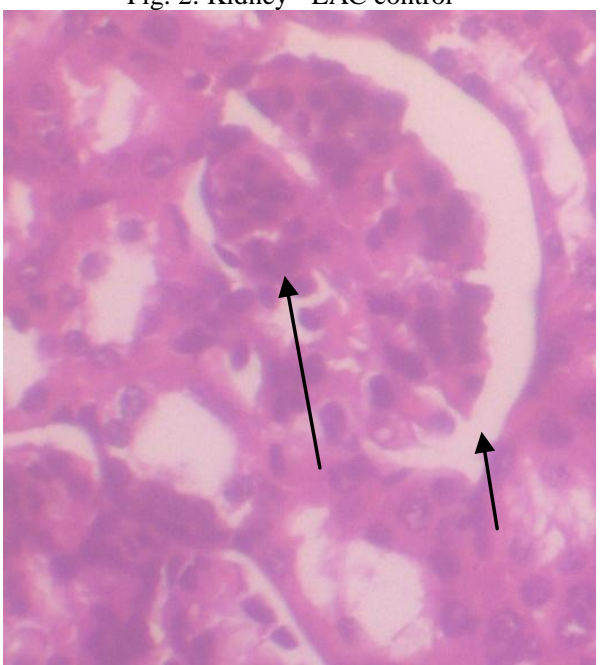

Fig. 4: Kidney - Fluorouracil control

The standard group receiving 5 Fluoro Uracil, The Section studied shows liver parenchyma with intact architecture. The liver parenchyma and central veins appear normal. Most of the sinusoids appear dilated and congested. The Kidney's architecture is intact. The Glomerulus shows normal cellularity. Tubules appear normal. Some of the blood Vessels are dilated and congested. The 3rd group receiving 100mg of extract of Kigelia Africana Section studied shows liver parenchyma with intact architecture. Some of the sinusoids appear dilated. There are few periportal inflammatory infiltration comprising of predominantly lymphocytes. Few of the veins appear congested. Kidney's architecture is Intact. Glomerulus shows normal cellularity. The mesangium appear within normal limits. Tubules and Interstitium appear normal. And few blood vessels are congested.

\section{Discussion}

Cancer is a term describing conditions characterized by unscheduled and uncontrolled cellular proliferation. It is a very common disease, and its incidence is increasing at an average annual rate of 1.2\% [29]. Lately, there has been improvement in the treatment strategies of cancer, which has resulted in prolonged survival of patients with chronic cancer disease. However there is a growing need for additional means of cancer therapy, in the form of both palliative and curative treatments. The strategies available today, are sophisticated, and are only able to affect 50 to $60 \%$ of cancer patients, while the others will eventually die from the disease [30], [32].

The present study was carried out to evaluate the anticancer activity of flavonoid of Ruellia tuberosa in Ehrlich Ascites Carcinoma induced breast and solid tumour. The anticancer activity of Ruellia tuberosa was screened with respect to the following parameters: 
- Mean Survival Time,

- $\quad$ Percentage increase in life span (\%ILS),

- Tumour size,

- Body weight,

- Effect on haematological parameters,

- Histopathological Studies.
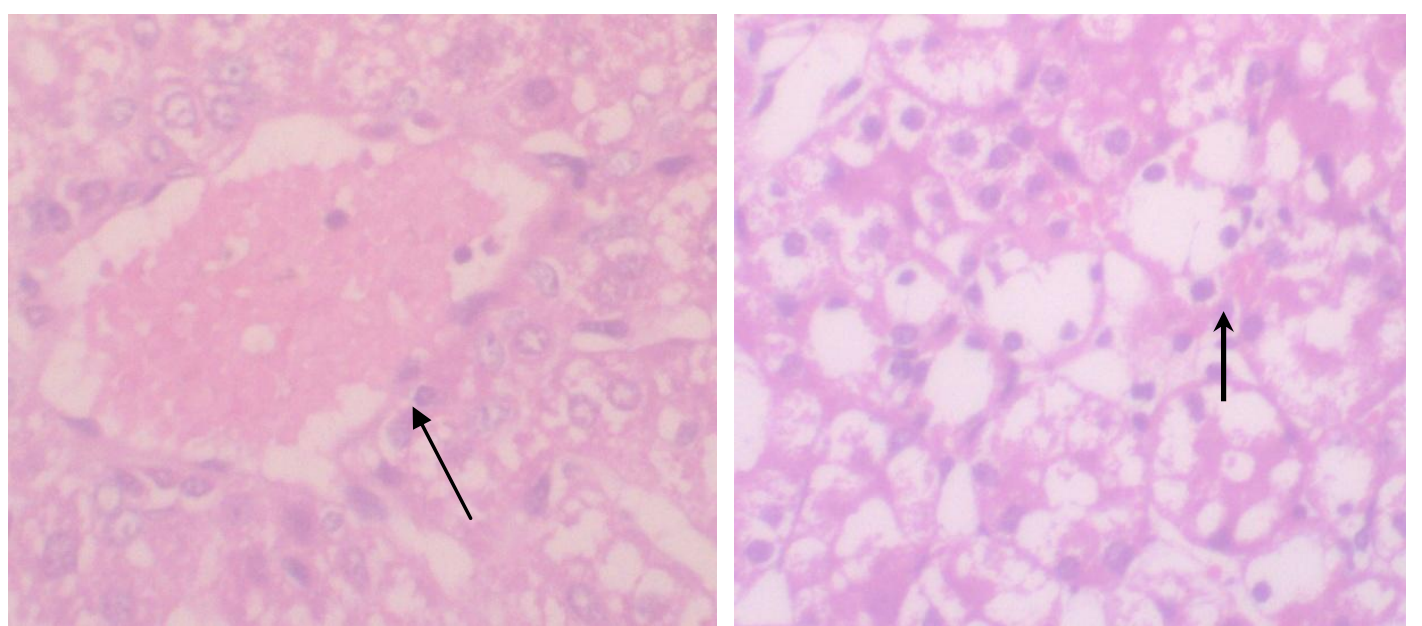

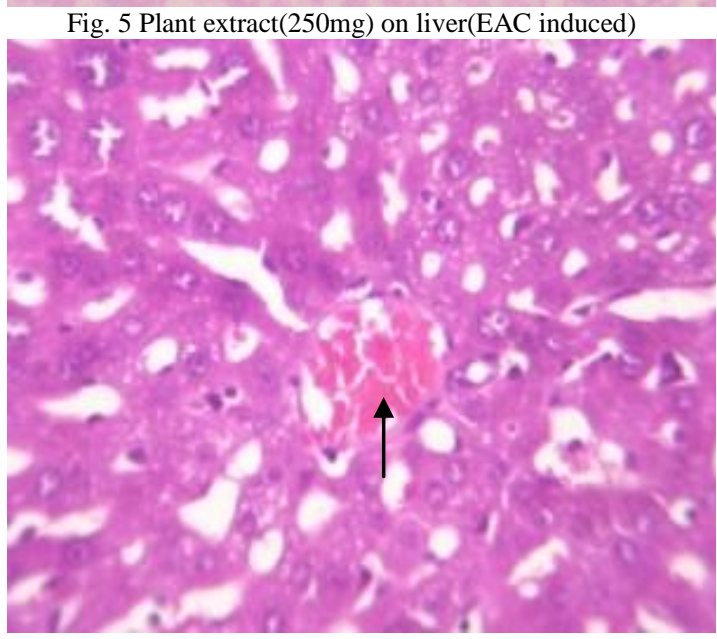

Fig. 7: Plant extract(500mg) on liver(EAC induced)
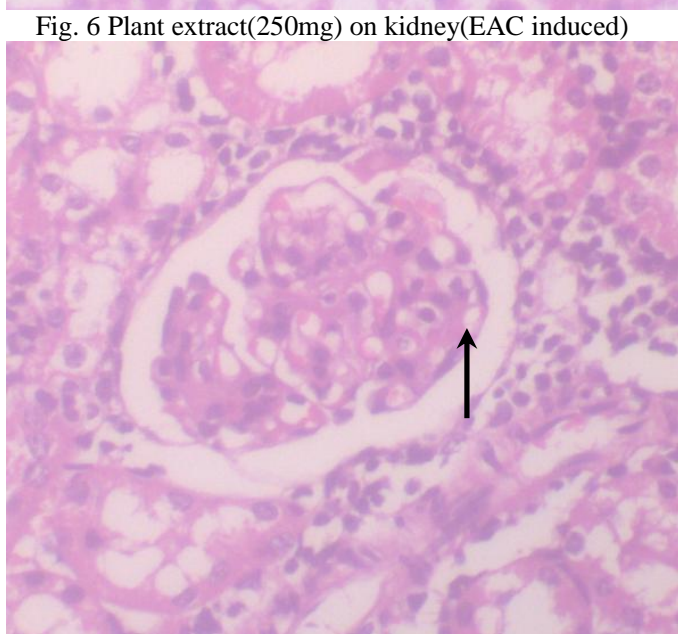

Fig. 8: Plant extract(500mg) on kidney (EAC induced)

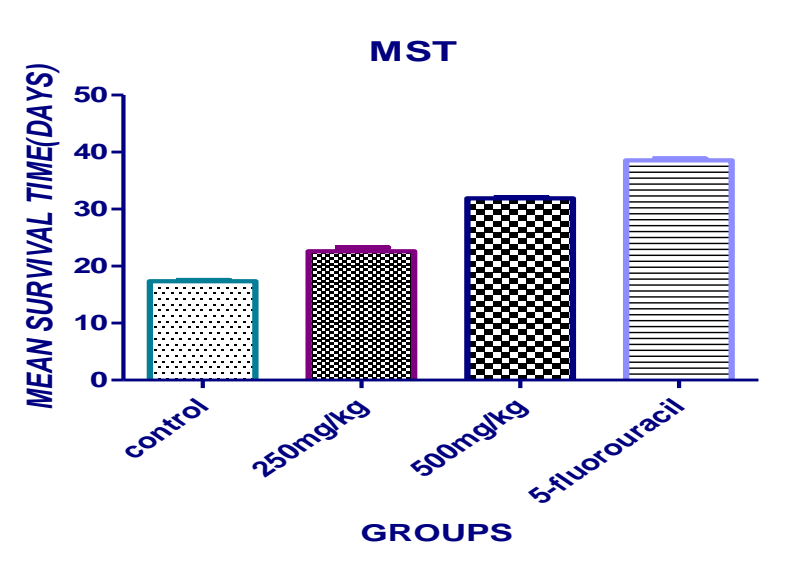

\%ILS

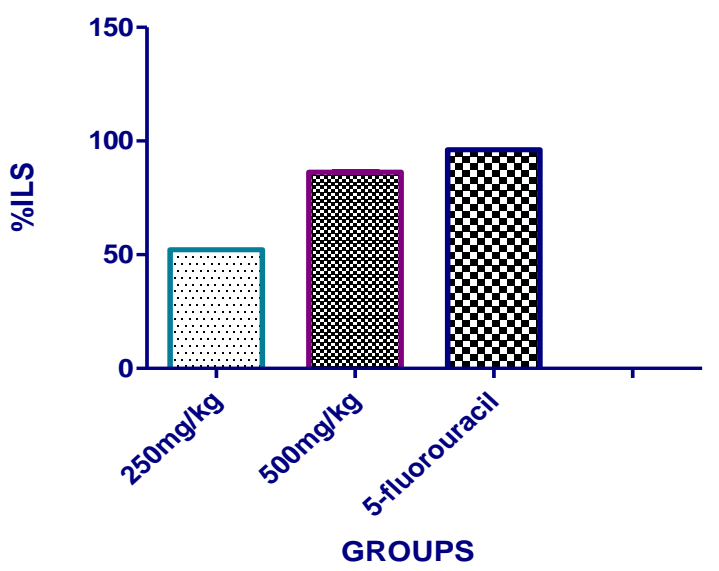




\section{BODY WEIGHT}

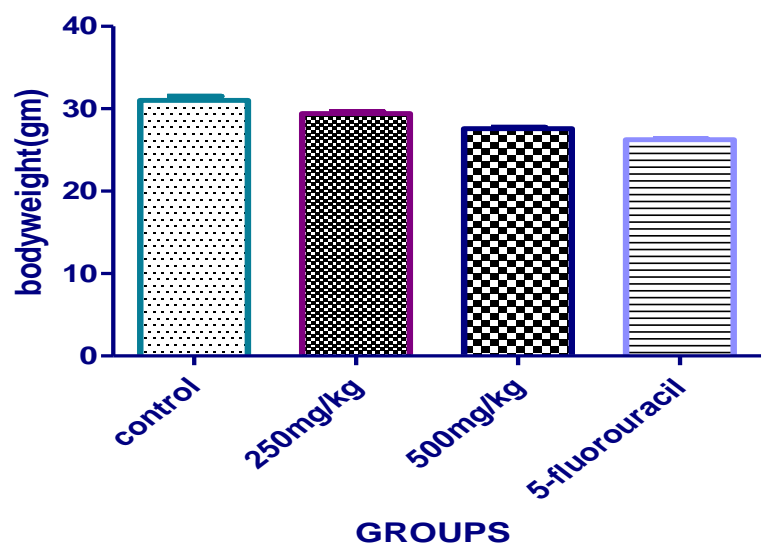

TUMOUR SIZE

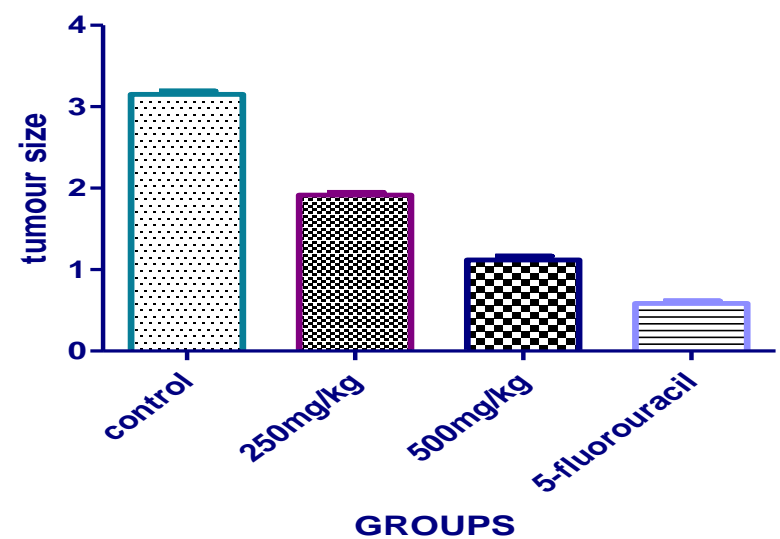

In Invivo studies, the reliable criteria for judging the value of anticancer drug are prolongation of life span, inhibition of gzain in average body weight and decrease of WBC from blood[33]. Besides these, decrease in the tumour volume and viable tumour cell count observed in the present experiment can be considered as an important indication of the reduction of tumour burden and enhancement of life span of EAC bearing mice. An increase in the life span of ascites bearing animals by $25 \%$ is considered as indicative of significant drug activity [34]. The results of the present study showed an anti tumour effect of pure compound extract of Ruellia tuberosa against EAC in swiss Albino mice. A significant $(\mathrm{P}<0.0001$ for the plant extract) enhancement of MST, decrement of gain of average body weight and decrease of WBC count were observed.

A growing body of research suggests that ROS play a crucial role in cancer development. Cancer cells produce high levels of the ROS superoxide anion

$(\mathrm{O} 2 \bullet-)$ and hydrogen peroxide $(\mathrm{H} 2 \mathrm{O} 2)$, and it has been demonstrated that an increase in the cellular levels of O2•-and $\mathrm{H} 2 \mathrm{O} 2$ can induce cell malignant transformation. Non-cytotoxic levels of $\mathrm{O} 2 \cdot-$ and $\mathrm{H} 2 \mathrm{O} 2$ can induce DNA alterations and play an important role in key aspects of carcinogenesis, including cell proliferation, apoptosis resistance, angiogenesis and invasion/metastasis. Accordingly, the malignant phenotype of cancer cells can be reversed just by increasing the levels of the $\mathrm{O} 2 \cdot--$ and $\mathrm{H} 2 \mathrm{O} 2$-detoxifying enzymes superoxide dismutase, catalase or glutathione peroxidase. Because Ruellia tuberosa contains flavonoid like leuteolin, 6-hydroxyluteolin-7-alpha-glucoside and its glycosides, leuteolin have known antioxidant properties, it makes sense to think that the antioxidant activity of this flavonoid is a key mechanism involved in its cancer preventive activity [35].

Usually, in cancer chemotherapy the major problems that are being encountered are of myelosuppression and anaemia. The anaemia encountered in tumour bearing mice is mainly due to reduction in RBC or Haemoglobin percentage, and this may occur due to iron deficiency or due to haemolytic or myelopathic conditions. The analysis of the haematological parameters showed minimum toxic effect in mice treated with the flavonoid plant extract of Ruellia tuberosa. After 20days of treatment, the flavonoid extract was able to reverse the changes in the haematological parameters consequent to tumour inoculation. This clearly indicates that the selected possess protective action on the haemopoietic system

\section{Conclusion}

In vivo studies showed that the extract of Ruellia tuberosa exhibited very good anticancer activity when compared with the standard drug. The activity was confirmed by significant enhancement of MST, decrement of gain in average body weight and decrease of WBC count were observed. On the other hand pure compound of Ruellia tuberosa can also be used as an adjuvant therapy in combination with the existing anticancer drugs like Fluorouracil or Methotrexate.

Based on the study we can conclude to the potential anticancer activity of flavonoid of Ruellia tuberosa and might be a promising anticancerous agent against breast tumor induced by Ehrlich Ascites Carcinoma. With the anti-tumor activity the observations suggest that the combination has a potent anticancer activity. Further studies are needed to characterize the anticancer activity of the selected extract to find out the exact mechanism involved so that it can be formulated and may be tried clinically. 


\section{References}

[1] Raju Senthil kumar, Balasubramanian Rajkapoor, Perumal Perumal, et.al. Antitumor activity of Prosopis glandulosa Torr. On Ehrlich Ascites Carcinoma (EAC) Tumor Bearing Mice. Iranian Journal of Pharmaceutical Research (2011); 10 (3):505-510.

[2] Raju Senthil Kumar, Balasubramanian Rajkapoor, Perumal Perumal. Antitumor and Cytotoxic Activities of Methanol Extract of Indigofera linnaei Ali. Asian Pacific Journal of Cancer Prevention 2011; 12:613-618.

[3] Meenakshi Sundaram, Satyajit Patra, Gunasingham Maniarasu. Antitumor activity of ethanol extracts of Gracilaria edulis (Gmelin) Silva on Ehrlich ascites carcinoma-bearing mice. Journal of Chineese Integrative Medicine 2012; 10(4):430-435.

[4] Brindha Durairaj and Arthi Dorai. Evaluation of Antitumor and in vivo antioxidant potentials of Nelumbo Nucifera Gaertn (white and pink) flowers in Ehrlich Ascites Carcinoma mice. Journal of Pharmacy Research 2010;3(10):2483-2487.

[5] Pandey CN, Medicinal Plants of Gujarat, Gujarat Ecological Education and Research Foundation, Gujarat, India, 2005.

[6] Medicinal Plants of the Guiana's (Guyana, Surinam, French Guiana).

[7] Chothani DL, Patel MB, Vaghasiya HU,et.al. "Review on Ruellia tuberosa (cracker plant)". Pharmacognosy Journal 2010; 2(12) :506-512.

[8] Suseela L and Prema S. "Pharmacognostic study on Ruellia tuberosa." Journal of Medicinal and Aromatic Plant Sciences 2007; $29: 117-122$.

[9] Reddy MB, Reddy KR and Reddy MN. "Ethnobotany of Cuddapah district, Andhra Pradesh, India." International Journal of Pharmacognosy 1991; 29(4):273-280.

[10] Kirtikar BD and Basu BD. Indian Medicinal Plants, vol. 3, International Book Distributors, Deheradun, India, 1935.

[11] The Wealth Of India, A Dictionary Of Indian, Raw Material and Industrial Product, Publication and Information Directorate, Council of Scientific and Industrial Research, New Delhi, India, 1972.

[12] Chiu NY and Chang KH. "The illustrated medicinal plants of Taiwan.” Mingtong Medical Journal 1995; $226: 1$.

[13] Chen FB, Wu AB, ShiehPH,et.al. "Evaluation of the antioxidant activity of Ruellia tuberosa," Food Chemistry 2006; 94(1):14-18.

[14] Lans CA, Creole remedies. Case studies of ethnoveterinary medicine in Trinidad and Tobago, Ph.D.Dissertation,Wageningen University, Wageningen, The Netherlands, 2001; 2992.

[15] [15]. Lans CA, "Ethnomedicines used in Trinidad and Tobago for urinary problems and diabetes mellitus," Journal of Ethnobiology and Ethnomedicine 2006; 2(45):1-11.

[16] Balick MJ, Kronenberg F, Ososki AL et al. "Medicinal plants used by latino healers for women's health conditions in New York City," Economic Botany 2000; 54(3):344-357.

[17] Chen FA, Wu AB, Shieh P, Kuo DH and Hsieh CY. "Evaluation of the antioxidant activity of Ruellia tuberosa," Food Chemistry 2006; 94(1):14-18.

[18] Wiart C, Hannah M, Yassim M, Hamimah H and Sulaiman M. "Anti-microbial activity of Ruellia tuberosa L”. American Journal of Chinese Medicine 2005; 33(4):683-685.

[19] Arun S, Giridharan P, Suthar A et al. Isolation of Tylocrebrine from Ruellia tuberosa through Bioassay Directed Column Chromatography and Elucidating its Anti-Cancer and Anti- Inflammatory Potential, 7th JointMeeting of GA, AFERP, ASP, PSI \& SIF, Athens, Greece, 2008.

[20] Arambewela LSR, Thambugala R and Ratnasooriya WD. "Gastroprotective activity of Ruellia tuberosa root extract in rats. Journal of TropicalMedicinal Plants 2003; 4(2):191-194.

[21] Alam MA, Subhan N, Awal M.A. et al. "Antinociceptive and anti-inflammatory properties of Ruellia tuberosa". Pharmaceutical Biology 2009; 47(3):209-214.

[22] Chwan-Fwu Lin, Yu-Ling Huang, Lee-Ying Cheng, Shuenn-Jyi Sheu and Chien-Chih Chen. Bioactive flavonoids from Ruellia tuberosa. J Chin Med 2006; 17(3):103-109.

[23] Abu-Sinna G, Esmat AM, Al-Zahaby S, et.al. Fractionation And charecterization of cerastes snake venom and the antitumor action of its lethal and non- lethal fractions. Toxicon 2003; 42:207-215.

[24] Kuttan G, Vasudevan DM, Kuttan R. Effect of a preparation from Viscum album on tumour development in vitro and in mice. J. Ethnopharmacol 1990; 29:35-41.

[25] D'Armour FE, Blood FR, Belden DA. The manual for laboratory work inmammalian physiology. 3rd ed. Chicago: The Uni-versity of Chicago Press; 1965.

[26] Wintrobe MM, Lee GR, Boggs DR, Bithel TC, Athens JW, Foerester. ClinicalHematology 5th ed. Philadelphia;1961.

[27] Ghosh MN. Toxicity studies, Fundamental of Experimental Pharmacology.Calcutta, India: Scientific book agency; 1984. Ponder B AJ., 2001Cancer genetics. Nature, 411:336-341.

[28] Ponder B AJ., 2001- Cancer genetics. Nature, 411:336-341.

[29] Verweij J., and De Jong M. J. A., 2003 Achievements and future of chemotherapy. European journal of cancer, 36:1479-1487.

[30] Talback M., Stenbeck M., Rosen M., Barlow L., and Glimelius B., 2003-Cancer survival in Sweden (1960-1998) developments across four decades. Acta oncology, 42:637-659.

[31] Socialstyrlesn ., 2004- cancer incidence in Sweden 2003. Statistics- health anddisease, 10. Online March 2005. www.sos.se/sos/statisti.htm.

[32] Clarkson BD, Burchenal JH. Preliminary screening of antineoplastic drugs. ProgClin Cancer 1965; 1:625-629.

[33] Andreani A, Scapini G, Galatulas I. Potential antitumor agents IX: synthesis andantitumor activity of two analogues of Ketocaine. J. Pharm. Sci $1983 ; 72: 814-819$.

[34] Hogland HC. Hematological complications of cancer chemotherapy. Semin Oncol 1982; 9:95-102.

[35] Fenninger LD, Mider GB. Energy and nitrogen metabolism in cancer. Adv Cancer Res 1954; 2:229-253. 